\title{
HUBUNGAN PENGETAHUAN DENGAN KECEMASAN IBU HAMIL MENJELANG PERSALINAN PADA MASA PANDEMI COVID-19
}

\author{
Riska Diana Putri ${ }^{1}$, Asri Mutiara Putri ${ }^{*}$, Ratna Purwaningrum ${ }^{3}$ \\ 1,3Program Studi Kedokteran Fakultas Kedokteran Universitas Malahayati \\ 2Program Studi Psikologi Fakultas Kedokteran Universitas Malahayati \\ *Korespondensi email asri@malahayati.ac.id
}

\section{ABSTRACT THE RELATIONSHIP BETWEEN KNOWLEDGE WITH PREGNANT WOMEN PRE LABOR ANXIETY DURING THE COVID-19 PANDEMIC}

Background Coronavirus Disease 2019 is currently a pandemic in almost all countries in the world. This pandemic outbreak can increase anxiety especially in pregnant women. One of the factors that can reduce the level of anxiety of pregnant women is knowledge.

Purpose This study was conducted to find out the relationship of knowledge with the level of anxiety of pregnant women ahead of childbirth in the era of the Covid-19 pandemic.

Methods The type of research used is Observational Analytics using Cross Sectional design. Respondets in this study were 59 pregnant women with a gestational age of 27-35 weeks before childbirth who checked their pregnancy to posyandu in Rajadesa Subdistrict, Ciamis Regency. The measuring instrument used is hamilton anxiety rating scale (HARS) and knowledge scale. The data was analyzed using Pearson Product Moment correlation tests.

The results of this study showed a significant negative relationship of -0.635 between knowledge and anxiety levels of pregnant women ahead of childbirth with a significance (p) of 0.000 . Further research can expand research samples from various regions in Indonesia so that a more comprehensive picture of anxiety in pregnant women in the era of the Covid-19 pandemic.

The conclusion is that there is a significant negative relationship between knowledge and anxiety in pregnant women before delivery and most pregnant women have good knowledge and do not experience anxiety.

Suggestions for health workers to be more intensive in providing counseling to pregnant women about the anxiety of pregnant women before delivery and optimizing referral services if there are complications during delivery in order to obtain appropriate action.

Keyword : Covid-19 pandemic, Knowledge, Anxiety

\section{ABSTRAK}

Latar Belakang Coronavirus Disease 2019 saat ini menjadi pandemi hampir di seluruh negara di dunia. Wabah pandemi ini dapat meningkatkan kecemasan terutama pada ibu hamil.Salah satu faktor yang dapat mengurangi tingkat kecemasan ibu hamil adalah pengetahuan.

Tujuan Penelitian ini dilakukan untuk mengetahui hubungan pengetahuan dengan tingkat kecemasan ibu hamil menjelang persalinan di era pandemi Covid-19.

Metode Jenis penelitian yang digunakan adalah Analitik Observasional dengan menggunakan desain Cross Sectional. Responden dalam penelitian ini adalah 59 ibu hamil dengan usia kehamilan 27-35 mimggu yang memeriksakan kehamilannya ke posyandu di Kecamatan Rajadesa Kabupaten Ciamis. Alat ukur yang digunakan adalah Hamilton Anxiety Rating Scale (HARS) dan skala pengetahuan. Data dianalisis menggunakan uji korelasi Pearson Product Moment.

Hasil penelitian ini menunjukan adanya hubungan negatif yang signifikan sebesar $-0,635$ antara pengetahuan dengan tingkat kecemasan ibu hamil menjelang persalinan dengan signifikansi (p) sebesar 0,000. Penelitian selanjutnya dapat memperluas sampel penelitian dari berbagai daerah di Indonesia sehingga diperoleh gambaran lebih menyeluruh tentang kecemasan pada ibu hamil di era pandemic Covid-19.

Kesimpulan ada hubungan negative signifikan antara pengetahuan dengan kecemasan pada ibu hamil menjelang persalinan dan sebagian besar ibu hamil memiliki pengetahuan baik dan tidak mengalami kecemasan. 


\section{JKM (Jurnal Kebidanan Malahayati),Vol 7,No.3.Juli 2021, ISSN (Print) 2476-8944 ISSN (Online) 2579-762X, Hal 426-431}

Saran bagi tenaga kesehatan agar lebih intensif dalam memberikan penyuluhan pada ibu hamil mengenai kecemasan ibu hamil menjelang persalinan dan mengoptimalkan pelayanan rujukan bila terdapat komplikasi pada saat persalinan agar dapat memperoleh tindakan yang tepat

Kata Kunci : Pandemi Covid-19, Pengetahuan, Kecemasan

\section{PENDAHULUAN}

Kehamilan ialah periode dimana seorang wanita menyimpan embrio atau fetus di dalam tubuhnya, seorang wanita yang lahir untuk pertama kalinya disebut primigravida (gravida 1) dan pada wanita yang belum pernah hamil disebut gravida 0 (Jahja, 2011). Kehamilan adalah suatu peristiwa yang melibatkan banyak perubahan fisiologis dan psikologis. Kehamilan merupakan fenomena kompleks yang menyebabkan perubahan psikologis dan sosial yang kuat, terutama pada ibu yang pertama kali hamil (Bjelica A \& Kapor-Stanulovic N, 2014).

Berdasarkan data Kemenkes tahun 2020 di Indonesia, terdapat $107.000(28,7 \%)$ ibu hamil yang mengalami kecemasan dalam menghadapi persalinan. Pada penelitian yang dilakukan oleh Novitasari menunjukkan kecemasan lebih banyak dialami pada ibu hamil primigravida yaitu sebanyak $66,2 \%$, dibandingkan dengan kecemasan pada ibu hamil multigravida sebanyak $42,2 \%$ (Novitasari T, 2013).

Bagi seorang ibu hamil, ketika menjelang persalinan cenderung mengalami kecemasan. Apabila cemas berlebihan, dampak atau masalah yang dapat terjadi yaitu menghambat dilatasi serviks normal, sehingga mengakibatkan partus lama dan meningkatkan persepsi nyeri dan bisa juga mengakibatkan perdarahan pada saat inpartu dan gawat janin karena ibu terlalu cemas dengan keadaannya (Janiwarty \& Pieter, 2013).

Kecemasan merupakan bagian dari respon emosional terhadap penilaian individu yang subjektif yang keadaannya dipengaruhi alam bawah sadar. Selama periode kehamilan hampir sebagian besar ibu hamil sering mengalami kecemasan. Setiap ibu hamil memiliki tingkat kecemasan yang berbeda dan tergantung pada sejauh mana ibu mempersepsikan kehamilannya (Janiwarty \& Pieter, 2013).

Coronavirus Diseases 2019 (COVID-19) adalah penyakit jenis baru yang belum pernah diidentifikasi sebelumnya pada manusia, virus ini dapat menimbulkan gejala mulai dari gejala ringan sampai gejala berat, seperti demam, batuk, nyeri tenggorokan, sepsis, pneumonia, dan syok septik (Yurianto, Ahmad, \& Wibowo, K.P., 2020).
Hasil penelitian Corbett G. A (2020) wanita hamil mengalami peningkatan kekhawatiran lebih dari $50,7 \%$ selama pandemic covid-19. Kekhawatiran ini meliputi kekhawatiran tentang kehamilan $66,7 \%$ dan perawatan bayi sebanyak $35 \%$ Kecemasan ini dipengaruhi oleh ancaman COVID-19 terhadap kehidupan ibu dan bayi, serta kekhawatiran tentang tidak terpenuhinya kebutuhan perawatan prenatal, ketegangan hubungan, dan isolasi sosial karena pandemi COVID-19 (Lebel, 2020).

Menurut beberapa faktor yang berhubungan dengan kecemasan yaitu pengetahuan, psikologi, ekonomi, pengalaman, dukungan keluarga serta dukungan suami. Ibu hamil dengan usia kurang dari 20 tahun atau lebih dari 35 tahun merupakan usia hamil resiko tinggi karena dapat terjadi kelainan atau gangguan pada janin, sehingga dapat menimbulkan kecemasan pada ibu hamil tersebut (Pieter, 2011)

Pengetahuan mempunyai peranan penting akan terjadinya tingkat kecemasan. Pengetahuan yang dimiliki ibu hamil akan menentukan cara pikir dan cara pandangnya tentang persalinan. Semakin banyak pengetahuan yang dimiliki ibu hamil tentang persalinan akan membentuk pikiran yang positif tentang persalinan sehingga ibu lebih siap menghadapi persalinan (Putranti,2014)

Berdasarkan paparan di atas penelitian ini dilakukan untuk mengkaji tentang kecemasan pada ibu hamil menjelang persalinan selama masa pandemi Covid-19. Kecemasan akan ditinjau dari pengetahuan mengingat besarnya peran pengetahuan pesalinan dalam menurunkan kecemasan ibu hamil.

\section{METODOLOGI PENELITIAN}

Penelitian ini merupakan penelitian Observasional Analitik dengan desain Cross Sectional. Sampel dalam penelitian ini adalah 59 ibu hamil menjelang persalinan yang memeriksakan kehamilannya ke posyandu di Kecamatan Rajadesa. Kriteria inklusi pada penelitian ini yaitu ibu hamil dengan usia kehamilan 27-35 minggu dan ibu hamil yang bersedia menjadi responden, dan kriteria ekslusi pada penelitian ini yaitu ibu hamil dengan usia kehamilan kurang dari 27 minggu atau lebih dari 35 minggu, ibu hamil dalam kadaan sakit 
dan ibu hamil dengan penyakit penyerta pada masa kehamilannya. Data dalam penelitian ini diperoleh menggunakan HARS untuk variabel kecemasan dan skala pengetahuan yang sudah teruji validitas ( $r$
$=>0,388)$ dan reliabilitasnya $(\alpha=0,943)$. Analisis data yang dilakukan untuk pengujian hipotesis adalah korelasi Pearson product moment.

\section{HASIL DAN PEMBAHASAN}

Tabel 1.

Karakteristik Responden

\begin{tabular}{|c|c|c|}
\hline Kategori & Frekuensi & Persentase (\%) \\
\hline \multicolumn{3}{|l|}{ Usia } \\
\hline$<20$ & 4 & $6,8 \%$ \\
\hline $21-35$ & 52 & $88,1 \%$ \\
\hline$>35$ & 3 & $5,1 \%$ \\
\hline \multicolumn{3}{|l|}{ Pendidikan } \\
\hline SD & 6 & $10,2 \%$ \\
\hline SMP & 22 & $37,3 \%$ \\
\hline SMA & 9 & $15,3 \%$ \\
\hline S1 & 20 & $33,9 \%$ \\
\hline S2 & 2 & $3,4 \%$ \\
\hline \multicolumn{3}{|l|}{ Pekerjaan } \\
\hline IRT & 35 & $39,3 \%$ \\
\hline Buruh/Petani/Nelayan & 4 & $6,8 \%$ \\
\hline wiraswasta & 8 & $13,6 \%$ \\
\hline PNS/TNI/POLRI & 12 & $20,3 \%$ \\
\hline \multicolumn{3}{|l|}{ Pendapatan Keluarga } \\
\hline$<$ Rp. 500 rb & 1 & $1,7 \%$ \\
\hline$<$ Rp. 1 jt & 11 & $18,6 \%$ \\
\hline Rp. 1 jt - Rp. 3 jt & 26 & $44,1 \%$ \\
\hline Rp. 3 jt - Rp. 5 jt & 14 & $23,7 \%$ \\
\hline$>$ Rp. $5 \mathrm{jt}$ & 7 & $11,9 \%$ \\
\hline \multicolumn{3}{|l|}{ Usia Kehamilan } \\
\hline 27-30 minggu & 33 & $55,9 \%$ \\
\hline 31-35 minggu & 26 & $44,1 \%$ \\
\hline \multicolumn{3}{|l|}{ Paritas } \\
\hline $\mathrm{Ke}-1$ & 19 & $32,2 \%$ \\
\hline $\mathrm{Ke}-2$ & 26 & $44,1 \%$ \\
\hline$>2$ & 14 & $23,7 \%$ \\
\hline Total & 59 & $100 \%$ \\
\hline
\end{tabular}

Sumber : Data Primer, 2021

Berdasarkan tabel 1 diketahui bahwa, sebagian besar responden berusia 21-35 tahun $(88,1 \%)$, berpendidikan SMP $(37,3 \%)$, bekerja sebagai ibu rumah tangga $(39,3 \%)$, dan berpendapatan keluarga berkisar Rp. 1.000.000 Rp. 3.000 .000 per bulan (44,1\%). Mayoritas ibu hamil memiliki usia kehamilan 27-30 minggu (55,9 $\%)$ dan mengalami kehamilan kedua $(44,1 \%)$.

Berdasarkan tabel 2 diketahui bahwa mayoritas ibu hamil yang menjadi responden di Kecamatan Rajadesa di era pandemi Covid-19 pada tahun 2021 memiliki pengetahuan baik $(45,8$ $\%)$.

Tabel 2.

Pengetahuan pada ibu hamil

\begin{tabular}{lcc}
\hline Pengetahuan & Frekuensi & Persentase(\%) \\
\hline Kurang & 16 & 27,1 \\
Cukup & 16 & 27,1 \\
Baik & 27 & 45,8 \\
\hline \multicolumn{1}{c}{ Jumlah } & 59 & 100 \\
\hline Sumber : Data Primer, 2021 &
\end{tabular}


JKM (Jurnal Kebidanan Malahayati),Vol 7,No.3.Juli 2021,

ISSN (Print) 2476-8944 ISSN (Online) 2579-762X, Hal 426-431

Tabel 3.

Distribusi Frekuensi Item Pertanyaan Pengetahuan Responden

\begin{tabular}{ccccc}
\hline \multirow{2}{*}{ Item Pertanyaan } & \multicolumn{2}{c}{ Jawaban Benar } & \multicolumn{2}{c}{ Jawaban Salah } \\
\cline { 2 - 5 } & Frekuensi $(\mathbf{n})$ & $\begin{array}{c}\text { Persentase } \\
(\%)\end{array}$ & Frekuensi (n) & $\begin{array}{c}\text { Persentase } \\
(\%)\end{array}$ \\
\hline Q1 & 49 & 83,1 & 10 & 16,9 \\
Q2 & 34 & 57,6 & 25 & 42,4 \\
Q3 & 41 & 69,5 & 18 & 30,5 \\
Q4 & 38 & 64,4 & 21 & 35,6 \\
Q5 & 46 & 78.0 & 13 & 22,0 \\
Q6 & 44 & 74,6 & 15 & 25,4 \\
Q7 & 44 & 74,6 & 15 & 25,4 \\
Q8 & 41 & 69,5 & 18 & 30,5 \\
Q9 & 36 & 61,0 & 23 & 39,0 \\
Q10 & 35 & 59,3 & 24 & 40,7 \\
Q11 & 39 & 66,1 & 20 & 33,9 \\
Q12 & 39 & 66,1 & 20 & 33,9 \\
Q13 & 43 & 72,9 & 16 & 27,1 \\
Q14 & 40 & 67,8 & 19 & 32,2 \\
Q15 & 41 & 69,5 & 18 & 30,5 \\
Q16 & 47 & 79,7 & 12 & 20,3 \\
Q17 & 45 & 76,3 & 14 & 23,7 \\
Q18 & 43 & 72,9 & 16 & 27,1 \\
Q19 & 42 & 71,2 & 17 & 28,8 \\
Q20 & 42 & 71,2 & 17 & 28,8 \\
\hline
\end{tabular}

Sumber : Data Primer, 2021

Berdasarkan tabel 3 dapat diketahui pengetahuan kurang terdapat pada item pertanyaan $2(42,4 \%), 4(35,6 \%), \quad 9(39 \%)$, dan $10(40,7 \%)$ yaitu pengetahuan mengenai dampak perubahan psikologis pada trimester ketiga dan perubahan psikologis pada trimester ketiga, kemudian pengetahuan baik terdapat pada item pertanyaan 1 (83,1\%), $16(79,7 \%), 6(74.6 \%)$, dan 17 (76,3\%) yaitu pengetahuan mengenai definisi kehamilan, definisi kehamilan trimester III, dan faktor-faktor psikologis yang mempengaruhi masa hamil.

Berdasarkan tabel 4 diketahui bahwa mayoritas ibu hamil yang menjadi responden di Kecamatan Rajadesa di era pandemi Covid-19 pada tahun 2021 tidak mengalami kecemasan $(62,7$ $\%)$.
Tabel 4.

Kecemasan Ibu Hamil Menjelang Persalinan

\begin{tabular}{lcc}
\hline \multicolumn{1}{c}{ Kecemasan } & Frekuensi & $\begin{array}{c}\text { Persentase } \\
(\%)\end{array}$ \\
\hline Tidak ada kecemasan & 37 & $62,7 \%$ \\
Kecemasan ringan & 22 & $37,3 \%$ \\
\hline Total & 59 & $100 \%$ \\
\hline Sumber : Data Primer, 2021 & \\
\multicolumn{3}{c}{ Berdasarkan tabel 5 diatas diperoleh nilai p } \\
$<0,01$ yang menunjukan adanya hubungan yang \\
bermakna antara pengetahuan dengan tingkat \\
kecemasan ibu hamil menjelang persalinan. \\
Hubungan bersifat negative dengan kekuatan \\
korelasi sedang, artinya semakin tinggi \\
pengetahuan yang diperoleh ibu hamil, maka \\
semakin rendah kecemasan yang dirasakan.
\end{tabular}


Tabel 5.

Uji korelasi Pearson-Product Moment Pengetahuan dengan Kecemasan Ibu Hamil Menjelang Persalinan

\begin{tabular}{|c|c|c|c|c|c|c|c|c|}
\hline \multirow{3}{*}{ Pengetahuan } & \multicolumn{4}{|c|}{$\begin{array}{l}\text { Tingkat Kecemasan dalam } \\
\text { Menghadapi Persalinan }\end{array}$} & & & \multirow{3}{*}{$\begin{array}{c}\text { Pearson } \\
\text { Corelation ( } r)\end{array}$} & \multirow{3}{*}{ P Value (p) } \\
\hline & \multicolumn{2}{|c|}{$\begin{array}{l}\text { Tidak ada } \\
\text { Kecemasan }\end{array}$} & \multicolumn{2}{|c|}{$\begin{array}{l}\text { Kecemasan } \\
\text { Ringan }\end{array}$} & \multicolumn{2}{|c|}{ Jumlah } & & \\
\hline & $\mathbf{N}$ & $\%$ & $\mathrm{~N}$ & $\%$ & $\mathbf{N}$ & $\%$ & & \\
\hline Kurang & 3 & 5,1 & 13 & 22,0 & 16 & 27,1 & & \\
\hline Cukup & 9 & 15,3 & 7 & 11,9 & 16 & 27,1 & $-.635^{\star \star}$ & .000 \\
\hline Baik & 25 & 42,4 & 2 & 3,4 & 27 & 45,8 & & \\
\hline Jumlah & 37 & 62,7 & 22 & 37,3 & 59 & 100 & & \\
\hline
\end{tabular}

Sumber : Data Primer, 2021

\section{PEMBAHASAN}

Hasil penelitian menemukan mayoritas ibu hamil di Kecamatan Rajadesa memiliki pengetahuan yang baik yang dilatar belakangi dengan mudahnya mengakses informasi yang didapatkan melalui, pengalaman orang lain, media (buku KIA, televisi), promkes serta konseling keluarga yang dilakukan oleh tenaga kesehatan di Puskesmas Kecamatan Rajadesa. Pengetahuan dipengaruhi oleh factor pendidikan, berdasarkan hasil penelitian mayoritas responden dengan pengetahuan baik berasal dari responden dengan pendidikan yang tinggi.

Pengetahuan yang dimiliki ibu hamil akan menentukan cara pikir dan cara pandangnya tentang persalinan. Semakin banyak pengetahuan yang dimiliki ibu hamil tentang persalinan akan membentuk pikiran yang positif tentang persalinan sehingga ibu lebih siap menghadapi persalinan. (Putranti, 2014).

Berdasarkan tabel 3 didapatkan dari kelima aspek pengetahuan, pengetahuan baik terdapat pada aspek pengetahuan mengenai dampak perubahan psikologis pada trimester ketiga dan perubahan psikologis pada trimester ketiga. Dengan pengetahuan yang baik ibu akan mempunyai kesiapan yang matang untuk dapat menghadapai persalinan sehingga dapat mengantisipasi sedini mungkin jika terjadi kegawatdaruratan dalam proses persalinan (Putranti, 2014).

Hasil penelitian juga menunjukkan bahwa mayoritas ibu hamil tidak mengalami kecemasan menjelang persalinan di era pandemic covid-19, hal ini dikarenakan masih rendahnya kasus covid-19 di Kecamatan Rajadesa selain itu juga responden memiliki pengetahuan yang baik akan bahaya covid-19 sehingga responden meningkatkan usaha peningkatan kesehatan pribadi seperti mencuci tangan dengan sabun, menggunakan masker, menghindari keramaian, melakukan social distancing, dan mencari informasi di media social mengenai bahaya covid-19 dan pencegahannya.

Kecemasan merupakan gangguan alam perasaan, ketakutan atau kekhawatiran yang mendalam dan berkelanjutan, tidak mengalami gangguan dalam menilai realitas, keperibadian masih utuh, perilaku dapat terganggu tetapi masih dalam batas-batas normal (Hawari D. , 2013).

Berdasarkan uji Pearson Correllation didapatkan hubungan negative signifikan antara pengetahuan dengan tingkat kecemasan ibu hamil menjelang persalinan di era pandemi Covid- 19 . Hasil ini konsisten dengan temuan penelitian yang dilakukan oleh (Wulandari, 2018) bahwa ada hubungan yang signifikan antara pengetahuan ibu hamil tentang proses persalinan dengan tingkat kecemasan menghadapi persalinan

Menurut Pieter terdapat beberapa faktor yang berhubungan dengan kecemasan yaitu pengetahuan, psikologi, ekonomi, pengalaman, dukungan keluarga serta dukungan suami. Ibu hamil dengan usia kurang dari 20 tahun atau lebih dari 35 tahun merupakan usia hamil resiko tinggi karena dapat terjadi kelainan atau gangguan pada janin, sehingga dapat menimbulkan kecemasan pada ibu hamil tersebut (Pieter, 2011).

Pada masa pandemic covid-19 saat ini kecemasan yang dialami dilatarbelakangi oleh situasi yang tengah meliputi pasien, gangguan saluran pernafasan, berkurangnya kegiatan sosial, perasaan terhadap penolakan oleh masyarakat dan dinamika sosial masyarakat yang berubah drastis, kekhawatiran tentang tidak terpenuhinya kebutuhan perawatan prenatal, ketegangan hubungan, dan isolasi sosial karena pandemi (Cameron, 2020)

\section{SIMPULAN}

Berdasarkan hasil penelitian dapat disimpulkan ada hubungan negative signifikan antara pengetahuan dengan kecemasan pada ibu hamil menjelang persalinan dan sebagian besar ibu 


\section{JKM (Jurnal Kebidanan Malahayati),Vol 7,No.3.Juli 2021, \\ ISSN (Print) 2476-8944 ISSN (Online) 2579-762X, Hal 426-431}

hamil memiliki pengetahuan baik dan tidak mengalami kecemasan.

\section{SARAN}

Bagi ibu hamil ibu hamil diharapkan selalu memperhatikan kesehatan terutama mengenai faktor-faktor yang berhubungan dengan kecemasan menjelang persalinan. Bagi tenaga kesehatan agar lebih intensif dalam memberikan penyuluhan pada ibu hamil mengenai kecemasan ibu hamil menjelang persalinan dan mengoptimalkan pelayanan rujukan bila terdapat komplikasi pada saat persalinan agar dapat memperoleh tindakan yang tepat.Bagi peneliti lain dalam penelitian selanjutnya diharapkan untuk mengambil sampel lebih banyak hal ini bertujuan untuk keakuratan data yang lebih baik dalam penelitiannya.

\section{DAFTAR PUSTAKA}

Bjelica A, \& Kapor-Stanulovic N. 2014. Pregnancy as a Psychological Event. Medicinski pregled, 57(3-4):144-8.

Bobak. 2015. Buku Ajar Keperawatan Materernitas . Jakarta: ECG.

Cameron, E. E. 2020. Maternal Psychological Distress \& Mental Health Service Use During the COVID-19 pandemic. Journal of Affective Disorders

(May). doi:10.1016/j.jad.2020.07.081. Diakses pada 16 Oktober 2020

Corbett, G. A. 2020. Health anxiety and behavioural changes of pregnant women during the COVID-19 pandemic. European Journal of Obstetrics and Gynecology and Reproductive Biology, 249, pp.96-97. doi:0.1016/j.ejogrb.2020.04.022. Diakses pada 11 Oktober 2020
Hawari, D. 2013. Manajemen Stres, Cemas, dan Depresi. Jakarta: FKUI.

Jahja, Y. 2011. Psikologi Perkembangan. Jakarta: Kencana Prenada Media Group.

Janiwarty, B., and Pieter, H. 2013. Pendidikan Psikologi untuk Bidan. Yogyakarta: ANDI.

Kemenkes RI. 2020. Pedoman Bagi lbu Hamil, Bersalin, Nifas, dan Byi Bru Lhir di Era Pandemi Covid-19.

Lebel, C. e. 2020. Elevated depression and anxiety among pregnant individuals during the COVID-19 pandemic. (July).doi: 10.31234/osf.io/gdhkt. Diakses pada 15 Oktober 2020

Novitasari T, B. T. 2013. Keefektivan Konseling Kelompok Pra-Persalinan Untuk Menurunkan Tingkat Kecemasan Primigravida Menghadapi Persalinan. Developmental and Clinical Psychology, 6270.

Pieter. 2011. Pengantar Psikologi Untuk Kebidanan. Jakarta: Kencana Prenada.

Putranti, T. 2014. Hubungan Pengetahuan dan Sikap Tentang Persalinan dengan Kesiapan Primigravida Menghadapi Persalinan di BPM Yulianawati Kecamatan Kertosono Kabupaten Nganjuk. Surakarta : Universitas Sebelas Maret.

Wulandari, S. 2018. Hubungan Pengetahuan Primigravida Tentang Proses Persalinan dengan Tingkat Kecemasan dalam Menghadapi Persalinan di Puskesmas Kalasan. Yogyakarta. Jurnal Formil Kesmas Respati, Volume 3, Nomor 2

Yurianto, Ahmad, dan Wibowo, K.P., B. 2020. Pedoman Pencegahan dan Pengendalian Corona Virus Disease (Covid-19). Diakses pada 14 Oktober 2020 